\title{
Effect of Korean Red Ginseng Supplementation on Ocular Blood Flow in Patients with Glaucoma
}

\author{
Na Rae Kim, Ji Hyun Kim, and Chan Yun Kim* \\ Department of Ophthalmology, Institute of Vision Research, Yonsei University College of Medicine, Seoul 120-752, Korea
}

The purpose of this study was to evaluate the effect of Korean red ginseng (KRG) on ocular blood flow in patients with glaucoma. In a prospective, randomized, placebo-controlled, double-masked crossover trial, 36 patients with open-angle

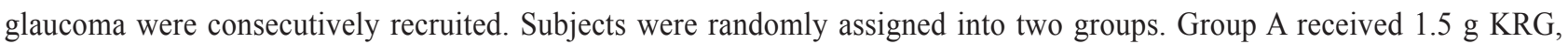
administered orally three times daily for 12 weeks, followed by a wash-out period of 8 weeks and 12 weeks of placebo treatment (identical capsules filled with $1.5 \mathrm{~g}$ corn starch). Group B underwent the same regimen, but took the placebo first and then KRG. Blood pressure, heart rate, and intraocular pressure were measured at baseline and at the end of each phase of the study. Visual field examination and ocular blood flow measurements by the Heidelberg Retina Flowmeter were performed at baseline and at the end of each phase of the study. Changes in blood pressure, heart rate, intraocular pressure, visual field indices, and retinal peripapillary blood flow were evaluated. Blood pressure, heart rate, intraocular pressure, and visual field indices did not change after placebo or KRG treatment. After KRG treatment, retinal peripapillary blood flow in the temporal peripapillary region significantly improved $(p=0.005)$. No significant changes were found in retinal peripapillary blood flow in either the rim region or the nasal peripapillary region ( $p=0.051$ and 0.278 , respectively). KRG ingestion appears to improve retinal peripapillary blood flow in patients with open-angle glaucoma. These results imply that KRG ingestion might be helpful for glaucoma management.

Keywords: Panax, Glaucoma, Ocular blood flow, Korean red ginseng, Visual fields

\section{INTRODUCTION}

Glaucoma, a leading cause of blindness in the world, is a group of diseases characterized by progressive optic neuropathy with a particular pattern of visual field (VF) loss. While mechanical and vascular causes have been proposed, the cause of glaucoma remains unclear [1,2]. The mechanical theory suggests that elevated intraocular pressure (IOP) is the most important risk factor for developing glaucomatous optic neuropathy. However, a substantial proportion of patients with primary open-angle glaucoma (POAG) consistently exhibit IOP values within the normal range of less than $22 \mathrm{mmHg}$, or so- called normal tension glaucoma (NTG) [3]. Moreover, POAG may still progress even if IOP is well controlled in the low teens [4]. The vascular theory considers glaucomatous optic neuropathy a consequence of insufficient ocular blood supply [5]. Epidemiological studies disclosed that low ocular perfusion increases the risk for glaucoma [6,7]. Several reports have identified that NTG is accompanied by an increased prevalence of vascular problems, including hemodynamic crises, hypercoagulability, arterial hypertension, arterial hypotension, high blood viscosity, elevated cholesterol levels,

\footnotetext{
(c) This is an Open Access article distributed under the terms of the Creative Commons Attribution Non-Commercial License (http://creativecommons.org/licenses/by-nc/3.0/) which permits unrestricted non-commercial use, distribution, and reproduction in any medium, provided the original work is properly cited.
}

Received 5 Jul. 2010, Revised 22 Jul. 2010, Accepted 23 Jul. 2010

*Corresponding author

E-mail: kcyeye@yuhs.ac

Tel: +82-2-2228-3570, Fax: +82-2-312-0541 
carotid artery disease, coronary artery disease, migraine, vasospasm, low blood velocity, and high resistance index in the orbital vessels [8-16]. Therefore, improving ocular blood flow may help the treatment of glaucoma. Several topical and systemic agents have been shown to improve ocular circulation in patients with glaucoma [17-21].

Ginseng (the root of Panax ginseng C.A. Meyer) has been known to be a valuable folk medicine in East Asian countries. Red ginseng is produced by steaming raw ginseng. Red ginseng is reported to be pharmacologically more active than raw ginseng in terms of chemical constituents (Rh4 and Rf2) that are produced in the steaming process [22]. In the past few years, the favorable effects of Korean red ginseng (KRG) have been reported in numerous diseases, including cardiovascular disease [2328], cerebrovascular disease [29], hyperlipidemic disease [30,31], sexual dysfunction [32,33], and Alzheimer's disease [34], though the exact explanation for these effects is not clear.

Favorable effects of ginseng roots on circulation have been reported, but there is no direct evidence that ginseng therapy can improve ocular blood flow in patients with glaucoma. In the present study, we assessed the effect of KRG ingestion on ocular blood flow in patients with open-angle glaucoma.

\section{MATERIALS AND METHODS}

\section{Study design}

We recruited 36 consecutive patients (11 men and 25 women) with open-angle glaucoma between May 2009 and August 2009. All patients were examined in a prospective, randomized, placebo-controlled, double-blind, crossover study. The study was conducted in accordance with the Declaration of Helsinki, and informed written consent was obtained from each participant. The Institutional Review Board of Severance Hospital, Yonsei University approved the study protocol.

Glaucomatous eyes were defined as those with a glaucomatous VF defect confirmed by two reliable VF examinations and by the appearance of a glaucomatous optic disc with typical loss of the neuroretinal rim as judged by slit-lamp biomicroscopy (cup-to-disc ratio $>0.7$; intereye cup asymmetry $>0.2$; or neuroretinal rim notching, focal thinning, disc hemorrhage, or vertical elongation of the optic cup). The NTG group was defined as those with untreated peak IOP lower than $21 \mathrm{mmHg}$ on three repeated measurements taken at different times on separate visits during clinical follow-up. The POAG group included those with IOP before treatment exceeding $21 \mathrm{mmHg}$ based on three measurements on different days. Subjects with a narrow angle, media opacity, a history of ocular surgery (other than uncomplicated glaucoma and cataract surgery), or other diseases affecting the VF were excluded.

Subjects who had changed systemic medication within 3 months were excluded, as this may affect blood flow. Individuals who were on medications with ginkgo biloba extract were excluded. Women of childbearing age were also excluded. Participants with controlled essential hypertension with stationary systemic medication were not excluded because of the high prevalence of this condition in elderly people. Individuals with uncontrolled systemic hypertension above $170 \mathrm{mmHg}$ systolic blood pressure or $100 \mathrm{mmHg}$ diastolic pressure were excluded.

\section{Administration of Korean red ginseng}

KRG (Jeong Kwan Jang; $300 \mathrm{mg} /$ capsule, total powder capsule, made by steaming and drying $100 \%$ 6 -year-old red ginseng roots) and placebo (identical capsules filled with corn starch $95.25 \%$, red ginseng fragrance $4.0 \%$, natural food color $0.15 \%$, and caramel food color $0.6 \%$ ) were provided by the Korea Ginseng Corporation (Daejeon, Korea).

Patients were randomly assigned to one of two treatments: oral administration of $1.5 \mathrm{~g}$ of KRG three times daily for 12 weeks, followed by a washout period of 8 weeks and then 12 weeks of placebo, or the same scheme, but with the placebo first. Eighteen patients were allocated to group A (regimen, $\mathrm{KRG} \rightarrow$ washout $\rightarrow$ placebo) and 18 to group B (regimen, placebo $\rightarrow$ washout $\rightarrow \mathrm{KRG}$ ).

Both participants and study staff (investigators and trial-coordinating center staff) were masked to treatment allocation. The order of the drug administration was randomized, and the medication was masked and coded by the manufacturer. An independent pharmacist dispensed either KRG or placebo according to a computer-generated, numbered randomization list. The KRG and the placebo were identical in appearance (shape, size, color, and taste) and in packaging. The boxes were labeled with study numbers and recorded in a separate database that identified which box contained the KRG and the placebo for each study number. These data were concealed until study completion.

\section{Measurement of arterial blood pressure and heart rate \\ Blood pressure and heart rate were assessed at base-}


line and at the end of each trial phase. Arterial blood pressure was measured on the upper arm by an automated oscillometric device. Three consecutive readings were obtained 5 minutes apart, and the last two were averaged for use in the analysis. Pulse rate was automatically recorded by the same device. All examinations were performed with the subject in the sitting position.

\section{Intraocular pressure and visual field examinations}

IOP was determined with the Goldmann tonometer at baseline and at the end of each phase. VF examinations were also performed at the same time. All tests were performed using standard automated perimetry (Humphrey Field Analyzer II with Swedish interactive thresholding algorithm standard 24-2; Carl Zeiss Meditec, Dublin, CA, USA). Each test included in the final analysis met the reliability criteria set by the manufacturer. All VF tests were performed on the same perimeter with best correction for near vision for each patient.

\section{Ocular blood flow measurement by the Heidelberg Retina Flowmeter}

Ocular blood flow was examined at baseline and at the end of each phase. To evaluate ocular blood flow, peripapillary retinal blood flow was obtained using the Heidelberg Retina Flowmeter (HRF; Heidelberg Engineering, Heidelberg, Germany). The technique of scanning laser Doppler flowmetry (SLDF) on the HRF has been described in detail elsewhere [35,36]. Briefly, the examination was performed in the sitting position without pupillary dilation after a short rest (about 10 to 15 minutes) at room temperature and with diffuse natural light. The laser Doppler frequency shift was measured by SLDF in each of 16,384 points in a retinal area of $2.7 \times 0.7 \mathrm{mM}$ within 2 seconds. Confocal optics of this device registered only the capillary blood flow of the superficial retinal layer of $300 \mu \mathrm{m}$. Detection of laser Doppler signals from deeper layers (choroid) was excluded due to the confocal characteristics of the optics. A map of the retinal blood flow was generated, encoded by the laser Doppler shift. Spatial resolution of the device was $10 \times 10 \mu \mathrm{m}$. The HRF scanned an intensity matrix of 256 points $\times 68$ lines $\times 128$ times using a repetition rate of $4,000 \mathrm{~Hz}$. Backscattered intensities of each scanned point were obtained as a function of time, resulting in 16,384 intensity-time curves. Collected intensity data of each retinal point of measurement were analyzed by discrete fast Fourier transformation, calculating the frequency laser Doppler shift for each point of measurement.

Acquired perfusion images were analyzed with automatic full-field evaluation of the perfusion images (SLDF-AFFPIA) [37,38]. SLDF-AFFPIA was used to analyze the perfusion images off-line after the experiments. For valid estimation of retinal blood flow by HRF, some requirements must be fulfilled: adequate brightness, no artificial movement, and a Doppler shift lower than $2,000 \mathrm{~Hz}$. To meet these requirements, the resultant perfusion images were processed by the SLDF-AFFPIA with respect to underexposed and overexposed pixels, saccades, and retinal vessel tree. In the first step of the statistical analysis, the operator marked saccades and the location of the rim area. In the second step, capillaries and vessels of the retinal vessel tree were identified automatically by a vessel detection algorithm based on the intensity and the perfusion image. After these procedures, retinal vessels with diameters larger than 30 $\mu \mathrm{m}$, underexposed or overexposed pixels, and saccades were automatically excluded from the perfusion image. These processes led to a perfusion map with vessels smaller than $30 \mu \mathrm{m}$ in diameter, without lines caused by saccades, and without pixels of inadequate reflectivity. Based on this processed perfusion map and all flow values, SLDF-AFFPIA automatically calculated the mean flow, SD, and cumulative frequency distribution curve in the scanned retinal area.

Ten images for each eye were acquired by a single operator, and the average value was used for analysis of retinal blood flow to improve reproducibility. When the operator drew the inner and outer rim contour lines, the program automatically calculated the flow. In each HRF image, the central rim area and the adjacent temporal and nasal peripapillary areas were analyzed by the AFFPIA program. All optic nerve heads (ONHs) were theoretically divided into three horizontal sections (superior, central, and inferior sections) (Fig. 1). In this study, only central ONH sections were considered.

\section{Statistical analysis}

For statistical analysis, one eye of each patient was randomly selected. Statistical analyses of the data were performed using the Wilcoxon signed-rank test, comparing blood pressure, heart rate, IOP, VF indices (including mean deviation and pattern standard deviation), and retinal blood flow parameters for each phase of the study. The Wilcoxon rank-sum test was used for the comparison of the two groups. Statistical analysis was performed using SPSS ver. 12.0 (SPSS Inc, Chicago, IL, USA). A $p$-value of less than 0.05 was considered significant. 


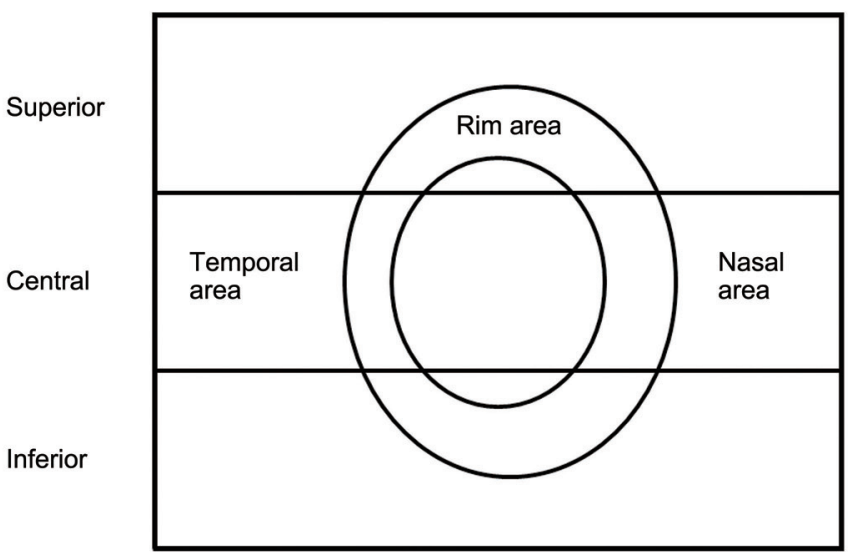

(A)

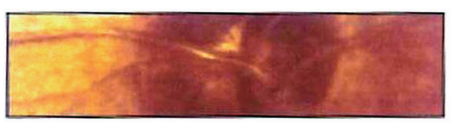

Region: temporal

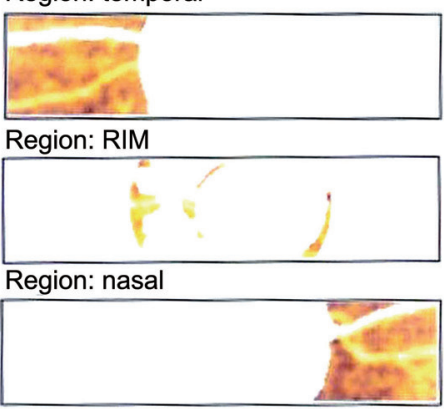

(B)

Fig. 1. (A) All optic nerve heads (ONHs) were theoretically divided into three horizontal sections (superior, central, and inferior). In this study, only central ONH sections were considered. (B) For each perfusion map, the automatic full-field evaluation of the perfusion images calculated three different flow measurements (rim flow, adjacent temporal flow, and adjacent nasal retinal flow) after drawing the inner and outer rim contour lines.

\section{RESULTS}

\section{Subjects}

All participants successfully completed the study. The mean age was $59.03 \pm 12.47$ years. Participants were 24 NTG patients $(66.7 \%)$ and 12 POAG patients (33.3\%) (Table 1).

Thirty-one patients $(86.1 \%)$ used topical antiglaucoma agents. The mean number of topical antiglaucoma agents used by each patient was $1.23 \pm 0.84$. Twenty-two patients $(61.1 \%)$ took systemic concomitant medication. Five patients took low-dose acetylsalicylic acid, and 13 patients took anti-hypertensive medications (Table 2). One patient complained of feeling feverish after KRG

Table 1. Baseline characteristics of patients studied

\begin{tabular}{lc}
\hline Variable & All $(n=36)$ \\
\hline No. of patients & 36 \\
Age $(\mathrm{yr})$ & $59.03 \pm 12.47$ \\
Female $(n, \%)$ & $25(69.4)$ \\
Diastolic BP $(\mathrm{mmHg})$ & $72.28 \pm 8.78$ \\
Systolic BP $(\mathrm{mmHg})$ & $130.42 \pm 14.17$ \\
Heart rate $(\mathrm{bpm})$ & $74.69 \pm 10.13$ \\
Height $(\mathrm{cm})$ & $159.20 \pm 6.38$ \\
Body weight $(\mathrm{kg})$ & $58.66 \pm 9.53$ \\
Body mass index $\left(\mathrm{kg} / \mathrm{m}^{2}\right)$ & $23.05 \pm 2.68$ \\
Glaucoma diagnosis & \\
$\quad$ Normal tension glaucoma $(n, \%)$ & $24(66.7)$ \\
$\quad$ Primary open angle glaucoma $(n, \%)$ & $12(33.3)$ \\
\hline
\end{tabular}

Data presented are mean \pm SD unless otherwise noted.

$\mathrm{BP}$, blood pressure; bpm, beats per minute. treatment, and two patients complained of feeling bloated after placebo treatment. No significant side effects related to KRG were found in this study.

\section{Blood pressure and heart rate}

The mean systolic blood pressure was $130.42 \pm 14.17$

Table 2. Ocular medications and systemic medications used in patients with glaucoma

\begin{tabular}{|c|c|c|}
\hline & & Number \\
\hline \multirow[t]{11}{*}{ Topical medication } & Betaxolol & 2 \\
\hline & Brimonidine & 1 \\
\hline & Brinzolamide & 6 \\
\hline & Dorzolamide & 1 \\
\hline & Bimatoprost & 1 \\
\hline & Latanoprost & 12 \\
\hline & Travoprost & 6 \\
\hline & Timolol & 1 \\
\hline & Timolol + brinzolamide & 1 \\
\hline & Timolol + dorzolamide & 5 \\
\hline & Timolol + latanoprost & 1 \\
\hline \multirow[t]{10}{*}{ Systemic medication } & Acetylsalicylic acid (low-dose) & 5 \\
\hline & Alpha adrenergic blocking agents & 1 \\
\hline & Angiotensin II receptor antagonist & 8 \\
\hline & Beta adrenergic blocking agents & 5 \\
\hline & Calcium-channel blockers & 2 \\
\hline & Dihydropyridines & 1 \\
\hline & Fibric acid derivatives & 1 \\
\hline & Levothyroxine & 4 \\
\hline & Statins & 6 \\
\hline & Thiazid diuretics & 2 \\
\hline
\end{tabular}


$\mathrm{mmHg}$, and the mean heart rate was $74.69 \pm 10.13$ beats/ min at baseline. KRG did not alter systemic arterial blood pressure in either KRG or placebo phases. No significant modifications in heart rate were noted after either KRG or placebo phases (Table 3).

\section{Intraocular pressure and visual field indices}

There were no significant changes in IOP or VF indices after either KRG or placebo phases (Table 4).

\section{Retinal blood flow}

For the rim and nasal area flow, no difference was found between baseline and 12 weeks of KRG treatment. However, a significant difference was found in temporal area flow. After the KRG phase, group A (18 patients) showed a significant difference in the blood flow of the temporal peripapillary area when compared with the baseline values (baseline vs. after KRG, 420.24 vs. 440.65 [median, no units], $p=0.039$ ). After the placebo phase, no significant modifications were detected when compared with the baseline $(p=0.877)$ (Table 5). After the placebo phase, group B showed no significant changes in blood flow parameters compared with the baseline values $(p=0.679)$. After the KRG phase, blood flow in the temporal peripapillary area significantly improved when com- pared with the baseline (baseline vs. after KRG, 415.85 vs. 459.36 [median, no units], $p=0.048$ ) (Table 5).

When all eyes of groups A and B were pooled and compared with pooled baseline values, a significant improvement was noted in retinal blood flow in the temporal peripapillary area after KRG treatment $(p=0.005)$. No significant changes were found in retinal peripapillary blood flow in the rim region or the nasal peripapillary region ( $p=0.051$ and 0.278 , respectively) (Table 5).

\section{DISCUSSION}

It is generally agreed that risk factors in addition to ocular hypertension may play an important role in the pathogenesis of open-angle glaucoma. According to the vascular or ischemic hypothesis, glaucomatous damage is caused, or at least facilitated, by inadequate perfusion of the proximal portion of the optic nerve. Findings that suggest vascular or perfusion abnormalities in NTG include an increased frequency of migraine headaches $[10,11]$ and Raynaud's phenomenon [8]. In support of a vascular role in NTG, Tokunaga et al. [16] found that NTG patients with a dip of more than $20 \%$ in nocturnal blood pressure had a higher incidence of VF progression than did those with a more physiologic dip of 10 to

Table 3. Blood pressure and heart rate responses after each phase of the study (patients are divided in two groups according to sequences of treatment)

\begin{tabular}{|c|c|c|c|c|c|c|c|c|c|c|}
\hline & \multicolumn{5}{|c|}{ Group A $(n=18)$} & \multicolumn{5}{|c|}{ Group B $(n=18)$} \\
\hline & Baseline & Ginseng & $p$-value ${ }^{1)}$ & Placebo & $p$-value ${ }^{1)}$ & Baseline & Placebo & $p$-value ${ }^{1)}$ & Ginseng & $p$-value ${ }^{1)}$ \\
\hline $\begin{array}{l}\text { Diastolic BP } \\
(\mathrm{mmHg})\end{array}$ & $\begin{array}{c}70.00 \\
(66.75-80.00)\end{array}$ & $\begin{array}{c}70.00 \\
(62.50-75.00)\end{array}$ & 0.058 & $\begin{array}{c}71.00 \\
(62.50-78.00)\end{array}$ & 0.727 & $\begin{array}{c}71.50 \\
(65.75-77.50)\end{array}$ & $\begin{array}{c}69.00 \\
(66.00-72.25)\end{array}$ & 0.379 & $\begin{array}{c}73.00 \\
(68.75-78.25)\end{array}$ & 0.368 \\
\hline $\begin{array}{l}\text { Systolic BP } \\
(\mathrm{mmHg})\end{array}$ & $\begin{array}{c}123.50 \\
(114.75-138.50)\end{array}$ & $\begin{array}{c}124.50 \\
(113.50-130.00)\end{array}$ & 0.074 & $\begin{array}{c}128.00 \\
(115.25-137.75)\end{array}$ & 0.844 & $\begin{array}{c}127.50 \\
(118.75-137.25)\end{array}$ & $\begin{array}{c}124.50 \\
(114.50-133.00)\end{array}$ & 0.078 & $\begin{array}{c}131.00 \\
(123.25-136.75)\end{array}$ & 0.407 \\
\hline $\begin{array}{l}\text { Heart rate } \\
(\mathrm{bpm})\end{array}$ & $\begin{array}{c}73.50 \\
(65.50-83.50)\end{array}$ & $\begin{array}{c}73.50 \\
(64.50-85.25)\end{array}$ & 0.981 & $\begin{array}{c}77.00 \\
(67.00-87.00)\end{array}$ & 0.093 & $\begin{array}{c}74.00 \\
(71.50-82.25)\end{array}$ & $\begin{array}{c}78.00 \\
(72.50-89.00)\end{array}$ & 0.107 & $\begin{array}{c}81.00 \\
(70.75-91.50)\end{array}$ & 0.076 \\
\hline
\end{tabular}

Group A sequence of treatment, ginseng $\rightarrow$ washout $\rightarrow$ placebo; group B sequence of treatment, placebo $\rightarrow$ washout $\rightarrow$ ginseng.

Data presented are median (interquartile range).

$\mathrm{BP}$, blood pressure; bpm, beats per minute.

${ }^{1)}$ Values for comparison with baseline (Wilcoxon signed-rank test).

Table 4. Intraocular pressure and visual field indices after each phase of the study (patients are divided in two groups according to sequences of treatment)

\begin{tabular}{|c|c|c|c|c|c|c|c|c|c|c|}
\hline & \multicolumn{5}{|c|}{ Group A $(n=18)$} & \multicolumn{5}{|c|}{ Group B $(n=18)$} \\
\hline & Baseline & Ginseng & $p$-value ${ }^{1)}$ & Placebo & $p$-value ${ }^{1)}$ & Baseline & Placebo & $p$-value ${ }^{1)}$ & Ginseng & $p$-value ${ }^{1)}$ \\
\hline IOP (mmHg) & $\begin{array}{c}13.50 \\
(12.00-15.00)\end{array}$ & $\begin{array}{c}13.50 \\
(11.75-14.25)\end{array}$ & 0.586 & $\begin{array}{c}13.00 \\
(10.75-15.00)\end{array}$ & 0.145 & $\begin{array}{c}14.00 \\
(12.00-16.00)\end{array}$ & $\begin{array}{c}13.00 \\
(12.00-14.00)\end{array}$ & 0.496 & $\begin{array}{c}13.50 \\
(11.75-15.00)\end{array}$ & 0.404 \\
\hline $\mathrm{MD}(\mathrm{dB})$ & $\begin{array}{c}-4.22 \\
(-6.13--1.53)\end{array}$ & $\begin{array}{c}-4.14 \\
(-6.18--1.95)\end{array}$ & 0.420 & $\begin{array}{c}-4.53 \\
(-7.13--2.91)\end{array}$ & 0.420 & $\begin{array}{c}-2.59 \\
(-4.64--1.07)\end{array}$ & $\begin{array}{c}-2.41 \\
(-3.97--0.87)\end{array}$ & 0.372 & $\begin{array}{c}-2.57 \\
(-4.79--1.17)\end{array}$ & 0.913 \\
\hline $\operatorname{PSD}(\mathrm{dB})$ & $\begin{array}{c}2.21 \\
(1.50-6.96)\end{array}$ & $\begin{array}{c}2.16 \\
(1.73-7.01)\end{array}$ & 0.586 & $\begin{array}{c}2.40 \\
(1.64-6.30)\end{array}$ & 0.845 & $\begin{array}{c}1.93 \\
(1.51-3.87)\end{array}$ & $\begin{array}{c}1.80 \\
(1.56-6.26)\end{array}$ & 0.556 & $\begin{array}{c}1.77 \\
(1.56-2.68)\end{array}$ & 0.896 \\
\hline
\end{tabular}

Group A sequence of treatment, ginseng $\rightarrow$ washout $\rightarrow$ placebo; group B sequence of treatment, placebo $\rightarrow$ washout $\rightarrow$ ginseng.

Data presented are median (interquartile range).

IOP, intraocular pressure; MD, mean deviation; $\mathrm{dB}$, decibel; PSD, pattern standard deviation.

${ }^{1)}$ Values for comparison with baseline (Wilcoxon signed-rank test). 
Table 5. Blood flow parameters after each phase of the study and after cross-over trial

\begin{tabular}{|c|c|c|c|c|c|c|}
\hline & \multicolumn{5}{|c|}{ Group A $(n=18)$} & \\
\hline & Baseline & Ginseng & $p$-value ${ }^{1)}$ & Placebo & $p$-value ${ }^{1)}$ & \\
\hline Temporal peripapillary area & $\begin{array}{c}420.24 \\
(322.92-523.41)\end{array}$ & $\begin{array}{c}440.65 \\
(336.15-626.24)\end{array}$ & 0.039 & $\begin{array}{c}375.27 \\
(260.50-615.33)\end{array}$ & 0.877 & \\
\hline Neuroretinal rim area & $\begin{array}{c}411.53 \\
(291.99-531.53)\end{array}$ & $\begin{array}{c}442.42 \\
(336.99-642.57)\end{array}$ & 0.078 & $\begin{array}{c}384.88 \\
(236.45-482.78)\end{array}$ & 0.959 & \\
\hline \multirow[t]{3}{*}{ Nasal peripapillary area } & $\begin{array}{c}305.21 \\
(224.71-455.84)\end{array}$ & $\begin{array}{c}323.97 \\
(236.07-503.53)\end{array}$ & 0.647 & $\begin{array}{c}279.08 \\
(224.24-415.69)\end{array}$ & 0.910 & \\
\hline & \multicolumn{6}{|c|}{ Group B $(n=18)$} \\
\hline & Baseline & Placebo & $p$-value ${ }^{1)}$ & Ginseng & $p$-value ${ }^{1)}$ & \\
\hline Temporal peripapillary area & $\begin{array}{c}415.85 \\
(337.50-552.49)\end{array}$ & $\begin{array}{c}395.95 \\
(322.79-470.35)\end{array}$ & 0.679 & $\begin{array}{c}459.36 \\
(360-94-696.56)\end{array}$ & 0.048 & \\
\hline Neuroretinal rim area & $\begin{array}{c}371.68 \\
(287.50-515.89)\end{array}$ & $\begin{array}{c}325.43 \\
(246.48-410.28)\end{array}$ & 0.472 & $\begin{array}{c}372.52 \\
(312.02-552.24)\end{array}$ & 0.267 & \\
\hline \multirow[t]{3}{*}{ Nasal peripapillary area } & $\begin{array}{c}302.68 \\
(222.44-477.36) \\
\end{array}$ & $\begin{array}{c}266.95 \\
(240.71-355.06) \\
\end{array}$ & 0.528 & $\begin{array}{c}319.21 \\
(222.81-454.19)\end{array}$ & 0.349 & \\
\hline & \multicolumn{6}{|c|}{ All $(n=36)$} \\
\hline & Baseline & Ginseng & $p$-value ${ }^{1)}$ & Placebo & $p$-value ${ }^{1)}$ & $p$-value $\mathrm{e}^{2)}$ \\
\hline Temporal peripapillary area & $\begin{array}{c}415.85 \\
(333.91-531.12)\end{array}$ & $\begin{array}{c}459.36 \\
(345.95-681.65)\end{array}$ & 0.005 & $\begin{array}{c}393.93 \\
(290.03-478.69)\end{array}$ & 0.898 & 0.039 \\
\hline Neuroretinal rim area & $\begin{array}{c}386.91 \\
(299.61-523.66)\end{array}$ & $\begin{array}{c}395.22 \\
(324.13-566.91)\end{array}$ & 0.051 & $\begin{array}{c}360.11 \\
(251.02-444.44)\end{array}$ & 0.510 & 0.066 \\
\hline Nasal peripapillary area & $\begin{array}{c}302.68 \\
(227.55-462.64)\end{array}$ & $\begin{array}{c}320.44 \\
(232.35-462.40)\end{array}$ & 0.278 & $\begin{array}{c}269.97 \\
(239.60-392.10)\end{array}$ & 0.598 & 0.255 \\
\hline
\end{tabular}

Group A sequence of treatment, ginseng $\rightarrow$ washout $\rightarrow$ placebo; group B sequence of treatment, placebo $\rightarrow$ washout $\rightarrow$ ginseng.

Data presented are median (interquartile range).

${ }^{1)}$ Values for comparison with baseline (Wilcoxon signed-rank test).

${ }^{2}$ Values for comparing ginseng and placebo (Wilcoxon rank-sum test).

$20 \%$. Systemic hypotension may also have a deleterious effect by creating insufficient perfusion pressure in the optic disc $[14,15]$.

The vasoactive effect could be useful in glaucoma; there is growing evidence that in some patients, glaucoma is associated with vascular dysregulation and lower perfusion pressure. Many authors have shown that vascular resistance downstream from the central retinal and posterior ciliary arteries is increased in glaucoma $[5,10,13$ 15]. Several studies have shown blood flow or blood velocity differences between normal, healthy subjects and glaucomatous ones [39,40]. Improving ocular blood flow together with reducing IOP may have a rationale in the treatment of glaucoma.

Several techniques for ocular blood flow evaluation have been introduced to clinical ophthalmology. However, these techniques have shown an uncertain reliability. In addition, it has not been determined which hemodynamic variables of blood supply (i.e., ophthalmic artery, posterior ciliary arteries, or central retinal artery) are appropriate to investigate with respect to the pathogenetic aspects of glaucoma. In this study, we utilized a commonly used SLDF device, HRF, which measures peripapillary retinal blood flow. Previous studies using HRF have reported significant decreases in $\mathrm{ONH}$ blood flow and juxtapapillary blood flow in open-angle glaucoma [41-43]. Because HRF takes $2 \mathrm{sec}$ to capture a topographic image when working from the top left to the bottom right [36], the resulting image is subject to special heterogeneity in circulatory parameters due to heart beat-associated pulsations [44]. Newer image software (AFFPIA) that uses the entire field of topographic images was reported to improve reliability [37,45-47]. The AFFPIA full-field option provides the highest reliability because it includes the largest possible image area for analysis and automatically adjusts for the quality of the topographic image, "auto-cleaning" and masking any extra-wide vessels, $\mathrm{ONH}$, and over- or under-exposed pixels [37]. In addition, each measurement was performed ten times in a chosen region to improve accuracy in ocular blood flow assessment.

KRG has been demonstrated to be effective in numerous vascular diseases [23-34]. The authors believed that KRG supplementation in open-angle glaucoma patients might be helpful for improving ocular blood flow. Theoretically, it may provide a protective effect on glaucoma progression. Our study using HRF to measure ocular blood flow suggests that KRG administration can be beneficial for retinal peripapillary blood flow in the temporal area in patients with open-angle glaucoma. 
However, in the nasal peripapillary and rim areas, no difference was found. Differences in IOP, systemic blood pressure, and VF indices before and after KRG administration were not significant. In addition, perfusion pressure measured before KRG administration did not change after KRG administration (data not shown here). It is not certain to what extent favorable influence could be exerted on preventing disease progression by the improvement of ocular blood flow in the confined juxtapapillary temporal area. In addition, the reason that a significant difference after KRG administration was found only in the temporal peripapillary area should be further studied.

This study has several limitations that require consideration. First, the limited duration of our study did not allow us to predict how long the effects of KRG administration would last. The duration of the effect and optimal administration schedule for KRG treatment must be investigated in future studies of glaucoma patients. Another limitation of this study is the large number of participants who used systemic medication. However, only patients whose systemic medication had not changed over the previous three months were enrolled to minimize the effect on ocular blood flow. In addition, the pharmacological agents taken by the participants in this trial stem from many different classes, and the small number of vasoactive substances used may have little implication on the results of this study. The use of topical antiglaucomatous therapy may also have affected the study results, but the effects are generally considered small. Third, HRF system measurements reflect only retinal blood flow. As mentioned above, it is unknown which source of blood flow plays a key role in the pathogenesis of glaucoma. Various techniques for the evaluation of ocular blood flow, including in the ophthalmic artery, short posterior ciliary arteries, and the central retinal artery, could strengthen the results of this study. Finally, the main limitation of this study is the small sample size. To distinguish the difference in ocular blood flow after ginseng treatment, 25 patients should have been recruited for each group, which would have provided sufficient statistical power to detect differences of 60 (no unit) $(\alpha=0.05$ and $\beta=20 \%)$. The present study is limited in terms of detecting significant differences in ocular blood flow after ginseng treatment. However, it was difficult to calculate appropriate sample sizes based on limited knowledge of the effect of ginseng treatment on ocular blood flow. More comprehensive analysis needs to be performed with a larger population.

In conclusion, significant increases in retinal blood flow were found in the temporal peripapillary areas after treatment with KRG as measured by HRF. Because numerous risk factors of a vascular nature have been reported to contribute to the pathogenesis of glaucoma, treatment to improve the ocular blood flow has some possibility of being helpful to prevent glaucoma progression. However, the effect is unpredictable because it has not been determined which source of blood supply affects glaucoma progression. A long-term prospective, placebo-controlled, randomized trial that takes into account the effects of KRG on glaucoma progression is warranted to investigate whether KRG is truly beneficial as a systemic treatment for glaucoma.

\section{ACKNOWLEDGEMENTS}

This work was supported by the 2009 grant from the Korean Society of Ginseng funded by Korea Ginseng Corporation.

\section{REFERENCES}

1. Fechtner RD, Weinreb RN. Mechanisms of optic nerve damage in primary open angle glaucoma. Surv Ophthalmol 1994;39:23-42.

2. Flammer J, Orgul S, Costa VP, Orzalesi N, Krieglstein GK, Serra LM, Renard JP, Stefansson E. The impact of ocular blood flow in glaucoma. Prog Retin Eye Res 2002;21:359-393.

3. Tielsch JM, Sommer A, Katz J, Royall RM, Quigley HA, Javitt J. Racial variations in the prevalence of primary open-angle glaucoma. The Baltimore Eye Survey. JAMA 1991;266:369-374.

4. Parc CE, Johnson DH, Oliver JE, Hattenhauer MG, Hodge DO. The long-term outcome of glaucoma filtration surgery. Am J Ophthalmol 2001;132:27-35.

5. Flammer J. The vascular concept of glaucoma. Surv Ophthalmol 1994;38 Suppl:S3-S6.

6. Bonomi L, Marchini G, Marraffa M, Bernardi P, Morbio $\mathrm{R}$, Varotto A. Vascular risk factors for primary open angle glaucoma: the Egna-Neumarkt Study. Ophthalmology 2000;107:1287-1293.

7. Tielsch JM, Katz J, Sommer A, Quigley HA, Javitt JC. Hypertension, perfusion pressure, and primary open-angle glaucoma. A population-based assessment. Arch Ophthalmol 1995;113:216-221.

8. Broadway DC, Drance SM. Glaucoma and vasospasm. Br J Ophthalmol 1998;82:862-870.

9. Gasser P, Flammer J. Blood-cell velocity in the nailfold capillaries of patients with normal-tension and high- 
tension glaucoma. Am J Ophthalmol 1991;111:585-588.

10. Phelps CD, Corbett JJ. Migraine and low-tension glaucoma: a case-control study. Invest Ophthalmol Vis Sci 1985;26:1105-1108.

11. Wang JJ, Mitchell P, Smith W. Is there an association between migraine headache and open-angle glaucoma? Findings from the Blue Mountains Eye Study. Ophthalmology 1997;104:1714-1719.

12. Wax MB, Tezel G, Saito I, Gupta RS, Harley JB, Li Z, Romano C. Anti-Ro/SS-A positivity and heat shock protein antibodies in patients with normal-pressure glaucoma. Am J Ophthalmol 1998;125:145-157.

13. Drance SM, Douglas GR, Wijsman K, Schulzer M, Britton RJ. Response of blood flow to warm and cold in normal and low-tension glaucoma patients. Am J Ophthalmol 1988;105:35-39.

14. Graham SL, Drance SM, Wijsman K, Douglas GR, Mikelberg FS. Ambulatory blood pressure monitoring in glaucoma. The nocturnal dip. Ophthalmology 1995;102:61-69.

15. Hayreh SS, Zimmerman MB, Podhajsky P, Alward WL. Nocturnal arterial hypotension and its role in optic nerve head and ocular ischemic disorders. Am J Ophthalmol 1994;117:603-624.

16. Tokunaga T, Kashiwagi K, Tsumura T, Taguchi K, Tsukahara S. Association between nocturnal blood pressure reduction and progression of visual field defect in patients with primary open-angle glaucoma or normal-tension glaucoma. Jpn J Ophthalmol 2004;48:380-385.

17. Carlsson AM, Chauhan BC, Lee AA, LeBlanc RP. The effect of brimonidine tartrate on retinal blood flow in patients with ocular hypertension. Am J Ophthalmol 2000;129:297301.

18. Chung HS, Harris A, Kristinsson JK, Ciulla TA, Kagemann C, Ritch R. Ginkgo biloba extract increases ocular blood flow velocity. J Ocul Pharmacol Ther 1999;15:233240.

19. Iester M, Altieri M, Michelson G, Vittone P, Traverso CE, Calabria G. Retinal peripapillary blood flow before and after topical brinzolamide. Ophthalmologica 2004;218:390396.

20. Luksch A, Rainer G, Koyuncu D, Ehrlich P, Maca T, Gschwandtner ME, Vass C, Schmetterer L. Effect of nimodipine on ocular blood flow and colour contrast sensitivity in patients with normal tension glaucoma. Br J Ophthalmol 2005;89:21-25.

21. Schmidt KG, von Ruckmann A, Pillunat LE. Topical carbonic anhydrase inhibition increases ocular pulse amplitude in high tension primary open angle glaucoma. $\mathrm{Br}$ J Ophthalmol 1998;82:758-762.

22. Baek NI, Kim DS, Lee YH, Park JD, Lee CB, Kim SI.
Ginsenoside Rh4, a genuine dammarane glycoside from Korean red ginseng. Planta Med 1996;62:86-87.

23. Kang SY, Kim ND. The antihypertensive effect of red ginseng saponin and the endothelium-derived vascular relaxation. Korean J Ginseng Sci 1992;16:175-182.

24. Chang SJ, Suh JS, Jeon BH, Nam KY, Park HK. Vasorelaxing effect by protopanaxatriol and protopanaxadiol of Panax ginseng in the pig coronary artery. Korean J Ginseng Sci 1994;18:95-101.

25. Kwak YS, Kyung JS, Song YB, Wee JJ, Park JD. Effect of crude saponin from red-ginseng efflux on blood biochemical parameters in acutely exposed to $2,3,7,8$ tetrachlorodibenzo- $\rho$-dioxin (TCDD). J Ginseng Res 2006;30:8-14.

26. Shin KS, Lee JJ, Kim YI, Jin YR, Yu JY, Park ES, Im JH, You SH, Oh KW, Lee MK, et al. Effect of Korean red ginseng extract on blood circulation in healthy volunteers: a randomized, double-blind, placebo-controlled trial. J Ginseng Res 2007;31:109-116.

27. Jin YR, Yu JY, Lee JJ, You SH, Chung JH, Noh JY, Im JH, Han XH, Kim TJ, Shin KS, et al. Antithrombotic and antiplatelet activities of Korean red ginseng extract. Basic Clin Pharmacol Toxicol 2007;100:170-175.

28. Sung J, Han KH, Zo JH, Park HJ, Kim CH, Oh BH. Effects of red ginseng upon vascular endothelial function in patients with essential hypertension. Am J Chin Med 2000;28:205-216.

29. Bae EA, Hyun YJ, Choo MK, Oh JK, Ryu JH, Kim DH. Protective effect of fermented red ginseng on a transient focal ischemic rats. Arch Pharm Res 2004;27:1136-1140.

30. Kwak YS, Kyung JS, Kim JS, Cho JY, Rhee MH. Antihyperlipidemic effects of red ginseng acidic polysaccharide from Korean red ginseng. Biol Pharm Bull 2010;33:468-472.

31. Hwang SY, Son DJ, Kim IW, Kim DM, Sohn SH, Lee JJ, Kim SK. Korean red ginseng attenuates hypercholesterolemia-enhanced platelet aggregation through suppression of diacylglycerol liberation in high-cholesterol-diet-fed rabbits. Phytother Res 2008;22:778-783.

32. Oh KJ, Chae MJ, Lee HS, Hong HD, Park K. Effects of Korean red ginseng on sexual arousal in menopausal women: placebo-controlled, double-blind crossover clinical study. J Sex Med 2010;7:1469-1477.

33. Choi HK, Choi YJ, Kim JH. Penile blood change after oral medication of Korean red ginseng in erectile dysfunction patients. J Ginseng Res 2003;27:165-170.

34. Heo JH, Lee ST, Chu K, Oh MJ, Park HJ, Shim JY, Kim M. An open-label trial of Korean red ginseng as an adjuvant treatment for cognitive impairment in patients with Alzheimer's disease. Eur J Neurol 2008;15:865-868. 
35. Bonner RF, Nossal R. Principles of laser-doppler flowmetry. In: Shepherd AP, Oberg PA, editors. Laser-Doppler blood flowmetry. Boston: Kluwer Academic Publishers, 1990. p.17-46.

36. Michelson G, Groh M, Langhans M, Schmauss B. 2-dimensional mapping and retinal and papillary microcirculation using scanning laser Doppler flowmetry. Klin Monbl Augenheilkd 1995;207:180-190.

37. Michelson G, Welzenbach J, Pal I, Harazny J. Automatic full field analysis of perfusion images gained by scanning laser Doppler flowmetry. Br J Ophthalmol 1998;82:12941300.

38. Michelson G, Warntges S, Leidig S, Lotsch J, Geisslinger G. Nimodipine plasma concentration and retinal blood flow in healthy subjects. Invest Ophthalmol Vis Sci 2006; 47:3479-3486.

39. Galassi F, Nuzzaci G, Sodi A, Casi P, Vielmo A. Color Doppler imaging in evaluation of optic nerve blood supply in normal and glaucomatous subjects. Int Ophthalmol 1992;16:273-276.

40. Gherghel D, Orgul S, Gugleta K, Gekkieva M, Flammer J. Relationship between ocular perfusion pressure and retrobulbar blood flow in patients with glaucoma with progressive damage. Am J Ophthalmol 2000;130:597-605.

41. Bohdanecka Z, Orgul S, Meyer AB, Prunte C, Flammer J. Relationship between blood flow velocities in retrobulbar vessels and laser Doppler flowmetry at the optic disk in glaucoma patients. Ophthalmologica 1999;213:145-149.

42. Griesser SM, Lietz A, Orgul S, Schotzau A, Hendrickson P, Flammer J, Haefliger IO. Heidelberg retina flowmeter parameters at the papilla in healthy subjects. Eur J Ophthalmol 1999;9:32-36.

43. Nicolela MT, Hnik P, Drance SM. Scanning laser Doppler flowmeter study of retinal and optic disk blood flow in glaucomatous patients. Am J Ophthalmol 1996;122:775783.

44. Michelson G, Schmauss B, Langhans MJ, Harazny J, Groh MJ. Principle, validity, and reliability of scanning laser Doppler flowmetry. J Glaucoma 1996;5:99-105.

45. Hafez AS, Bizzarro RL, Rivard M, Trabut I, Lovasik JV, Kergoat H, Lesk MR. Reproducibility of retinal and optic nerve head perfusion measurements using scanning laser Doppler flowmetry. Ophthalmic Surg Lasers Imaging 2003;34:422-432.

46. Iester M, Ciancaglini M, Rolle T, Vattovani O. Observer interpretation variability of peripapillary flow using the Heidelberg Retina Flowmeter. Eye (Lond) 2006;20:12461253.

47. Kreis AJ, Nguyen T, Rogers S, Wang JJ, Harazny J, Michelson G, Farouque HM, Wong TY. Reliability of different image analysis methods for scanning laser Doppler flowmetry. Curr Eye Res 2008;33:493-499. 